\title{
INCLUSÃO E EMANCIPAÇÃO SUBJETIVA, SOCIAL E CULTURAL DE PESSOAS COM DEFICIÊNCIA: REFLEXÕES À LUZ DAS CONTRIBUIÇÕES DE PAULO FREIRE
}

Luciana Stoppa dos Santos

Ana Claudia Alves Legore**

\begin{abstract}
RESUMO: O presente artigo se dedica a lançar algumas reflexões sobre o pensamento de Paulo Freire, suas contribuições relativas à importância da educação para o processo de libertação e emancipação dos oprimidos e a relação destes princípios éticos, políticos e educativos no que tange a educação de pessoas com Deficiência. Partimos do princípio de que um sujeito com Deficiência experimentou e ainda experimenta histórias de exclusão, humilhação e opressão e refletimos sobre como as políticas públicas nos diferentes campos não tem conseguido efetivamente garantir seu protagonismo e inclusão social. No campo da Educação, apontamos a garantia deste direito como aspecto fundamental para a tomada de consciência sobre a condição que vivencia no mundo e para a construção de um discurso próprio que possa pautar suas demandas e efetivamente transformar sua realidade. Por fim, propomos uma aproximação entre as ideias de Paulo Freire e Miguel Lopes Melero, pesquisador espanhol que se dedicou a lutar pela desconstrução de preconceitos acerca das pessoas com deficiência e suas potencialidades, elaborando um importante referencial teórico para ampliar a reflexão sobre a construção da autonomia pessoal, social e moral destes sujeitos.
\end{abstract}

Palavras-chave: Paulo Freire; Emancipação; Deficiência.

\begin{abstract}
This article aims at introducing some reflections concerning Paulo Freire's thoughts besides his contributions not only relating to the importance of education based on the process of liberation and emancipation of the opressed but also the relation of etical,political and educative principles regarding the education of the deficient people. First of all, it is of pivotal importance to highligh that when a deficient person lives an exclusion, humiliation and opressive situation the public pulitcs in all over the fileds, as we concern, are not able to guarantee eficientally the social inclusion. On the education field, we assure the guarantee of this social right as a fundamental aspect to develop the awareness of all the demands of a self-speech, then to transform the reality. Overall, we suggest an approximation between the ideas of Paulo Freire and Miguel Lopes Meleiro, a spanish researcher who devoted oneself to fight for the descontribution of the prejudice over people with deficiency and their potentials, thus perfecting

\footnotetext{
* Graduação em Psicologia pela Universidade Federal de São Carlos (UFSCar) e mestrado em Educação Especial pela UFSCar. Coordenadora na Associação Síndrome de Down de Ribeirão Preto.
}

** Graduação em Pedagogia pela Faculdade São Luís.
\end{abstract}


an important teorical referencial to amplify a refletion based on their contraction both personal, social and moral self-government

Keywords: Paulo Freire; Emancipation; Deficiency.

\section{DEFICIÊNCIA, EXCLUSÃO E EMANCIPAÇÃO}

Começamos este ensaio com um desafio bastante interessante: aprofundar a reflexão acerca das contribuições do pensamento de Paulo Freire para a Educação de Pessoas com Deficiência. Contudo, antes de adentrar o pensamento freireano é importante traçar um panorama histórico que nos dê a visão de como se constituiu a educação para este público no Brasil.

A literatura sobre o tema nos aponta aspectos que atravessam a vida da maioria das pessoas com deficiência: a invisibilidade e o assujeitamento. Historicamente, houve momentos em que a maioria da população no Brasil era iletrada e a escola (ainda) não funcionava como espaço classificatório de educáveis e não educáveis. Somente as crianças com algum tipo grave de deficiência se destacavam e eram destinadas a cuidados especiais em instituições (JANNUZZI, 2004). Pouco se investia em educação e muito menos na educação das pessoas com deficiência. Ainda segundo JANUZZI (2004) a sociedade inclusive se "protegia" das pessoas com deficiência, e na Constituição de 1824 deixava claro que estes sujeitos não tinham nenhum direito político.

Contudo, no Brasil e no mundo, acompanhando as mudanças sociais e culturais (Era Industrial, desenvolvimento da medicina) a sociedade começa a organizar as primeiras associações para pessoas com deficiência, voltadas para atender às necessidades de saúde e educação, iniciando aí a percepção de que as pessoas com deficiência deveriam integrar-se à sociedade. Surgem no Brasil, no início do século XX os primeiros Institutos de surdos e cegos e junto deles as propostas de educação profissionalizante. A Segunda Guerra assola o mundo e, além de eliminar milhares de pessoas com deficiência, deixa outros milhares

nessa condição. É nesse contexto de massacre e atrocidades que nasce a "Declaração Universal dos Direitos Humanos", grande marco na busca pela 
integração e aperfeiçoamento das ações voltadas às pessoas com deficiência (BRASIL, 2014)

Mazzota (1996) aponta que, embora no Brasil os dispositivos legais ao longo do tempo passarem a reconhecer o direito à educação das pessoas consideradas "excepcionais", o que era implementado em termos de ações políticas estava à margem do "sistema geral de educação". O autor destaca também o maciço investimento de dinheiro público em instituições privadas que realizavam atendimentos com caráter essencialmente terapêutico e assistencialista.

O modelo médico que pautou e pauta as práticas de cuidado às pessoas com deficiência, mesmo no âmbito de políticas de educação e assistência social por exemplo, veiculam uma lógica que torna a deficiência um atributo individual dos sujeitos, fruto de condições defeituosas e desse modo criam discursos "explicativos" para o fenômeno. Para Bosi (1992) tais discursos constituem uma tentativa de perpetuar um "caminho familiar" que guia a compreensão e as ações sobre o que, segundo ela, poderia ser considerado um "percurso imprevisto" pensando na condição de deficiência - e representam uma visão fragmentada da realidade, fortemente influenciada pela cultura. Pode-se então dizer, que o fenômeno da exclusão social da pessoa com deficiência foi legitimado por discursos que pretendem justificar por meio de explicações científicas (marcadamente médico-biológicas) uma suposta condição de déficit, de incompetência, de defasagem. O insucesso passa a ser responsabilidade dos sujeitos e não fruto das condições sociais econômicas e culturais às quais estão submetidos.

Avançamos, contudo, na reparação desta condição histórica de exclusão por meio da construção de dispositivos legais e da elaboração de marcos conceituais que garantem direitos à pessoa com Deficiência. Podemos citar a Convenção Internacional dos Direitos Da Pessoa com Deficiência (BRASIL; 2009), que traz inovações importantíssimas no que tange o conceito de Deficiência e ressalta a Dignidade e a Vida Independente como aspectos a serem assegurados; a Lei Brasileira de Inclusão - LBI (BRASIL, 2015) que institui a igualdade de direitos civis (capacidade legal) possibilitando autonomia 
moral à pessoa com deficiência. No campo da Educação, a Lei de Diretrizes e Bases (BRASIL, 1996) garante aos educandos com deficiência, transtornos globais do desenvolvimento e altas habilidades ou superdotação, a educação pública realizada preferencialmente na rede regular, contando com os apoios necessários (Atendimento Educacional Especializado), e a Política Nacional de Educação Especial (BRASIL 2008) estabelece as diretrizes e critérios para a oferta desta modalidade de ensino. Mais recentemente podemos citar o Plano Nacional de Educação (BRASIL, 2014) que apresenta metas claras para universalizar o ensino público e gratuito aos educandos de quatro a dezessete anos, público alvo da educação especial (estudantes com deficiência, transtornos globais do desenvolvimento e altas habilidades ou superdotação), bem como acessibilizar e qualificar o atendimento educacional especializado para estes estudantes.

É a partir do breve panorama sobre a condição histórica das pessoas com deficiência iniciamos as reflexões sobre as possibilidades de encontro do pensamento Freireano e o fenômeno da Inclusão Social e Educacional destas pessoas no Brasil. No início deste ensaio, apontamos a invisibilidade e o assujeitamento como aspectos que atravessam suas vidas, fenômenos produzidos e reproduzidos por discursos hegemônicos que relegam à alteridade deficiente o status de indivíduo "sub-humano", ou seja, vivem uma situação de opressão, fruto da história de desigualdade de oportunidades e de exclusão social à qual estão submetidos. Aberley (1987), quanto à opressão imposta às pessoas com deficiência, ressalta que a suposta condição de inferioridade é explicada por ideologias e grupos que perpetuam e justificam essa situação e indica que é fundamental discutir o fato de que as deficiências, bem como as ideologias que as sustentam, não são nem naturais e nem inevitáveis.

Se a deficiência não é fenômeno natural e inevitável, como devemos e podemos pensá-la de forma a produzir outro campo de reflexões que sejam esboço para a superação dessa condição de inferioridade e opressão? A Convenção Internacional dos Direitos da Pessoa com Deficiência, traz uma mudança importante no conceito de deficiência ao situá-la no encontro entre o indivíduo com determinadas limitações de ordem física, sensorial, intelectual ou 
mental e o ambiente, com as barreiras que impediriam sua plena participação na sociedade. Dessa forma, encarar a deficiência como fenômeno social e não biológico, implica pensar mudanças profundas nas estruturas da sociedade a fim de transpor barreiras físicas, arquitetônicas e atitudinais que permitam a esses indivíduos o gozo de seus direitos e liberdades, o protagonismo sobre suas vidas.

Bom mesmo é pensar se temos cumprido, enquanto sociedade, nossa obrigação de acessibilizar e equalizar as desigualdades históricas que calaram a alteridade deficiente. Quantas vezes presenciamos estes sujeitos lutando por si próprios, contra sua situação de opressão? Skliar (1999, p. 17) nos provoca profundamente afirmando:

\begin{abstract}
A alteridade deficiente raras vezes é vista como pertencendo a uma nação, sendo cidadãos e sujeitos políticos, articulando-se em movimentos sociais, possuidores de sexualidade, religião, etnia, classe social, idade, gênero e atores/produtores de narrativas próprias (...) A educação especial não é o ambiente único, natural e excludente, para entender a questão das identidades e as narrativas dos outros deficientes.
\end{abstract}

Qual seria o papel da Educação enquanto direito fundamental e fator preponderante para que as pessoas com Deficiência alcancem a plena participação em igualdade de condições na sociedade? Nossa reflexão caminha entendendo que a educação tem papel fundamental na emancipação intelectual, social, política e cultural dos indivíduos, na medida que possibilita a apropriação da linguagem como instrumento de transformação social. Paulo Freire nos diria que a palavra nos humaniza e que o papel da educação democrática e popular é possibilitar o desenvolvimento de uma linguagem própria, orgânica e que esse seria o caminho para a construção da cidadania (FREIRE, 2011).

Contudo, todos os marcos legais e conceituais que garantiriam direitos às pessoas com deficiência, não têm sido capazes de impedir a grande violação ao direito de participação e cidadania desses indivíduos. E a escola, espaço onde muitas das políticas inclusivas iniciaram há mais de 3 décadas, está longe de efetivamente garantir a educação para as diferenças, sendo que o que vemos, é a produção de uma retórica pedagógica sobre o trabalho com a diversidade que 
nada mais é do que a reprodução de formas de apropriação e dominação do outro. Para Skliar (2003), há a produção de um discurso para aplacar consciências, que busca incessantemente a compreensão do "outro diferente", e se destina a explicar a diferença para que ela não nos inquiete e, acima de tudo, para que essa inquietação não nos faça estranhar a nós mesmos. No mesmo caminho, Freire (1970) lembra da falsa generosidade dos opressores que perpetuam as injustiças como forma de realizar sua "generosidade" de forma permanente.

Vale pensar, também, que a efetiva inclusão e emancipação política e social da pessoa com deficiência não passa apenas pelos processos (ineficientes) de escolarização oferecidos hoje. Há uma dimensão fundamental que é a da participação e organização política desta população, protagonizando a defesa pelos seus direitos. Um exemplo histórico de como a militância pelos direitos não tem sido feita por esses sujeitos é a quantidade de associações de "pais", associações de "amigos", que se encarregam dessa "luta". Todo o respeito a estas instituições que realizam trabalhos importantes, mas não podemos deixar de destacar o movimento de tutela que a sociedade e as instituições exercem sobre as pessoas com deficiência. Outro dado importante é a observação da pífia participação dos usuários nas conferencias de direitos da pessoa com Deficiência que estão acontecendo desde o final do ano de 2016 - ou seja, estamos produzindo políticas de acesso e garantia de direitos a partir do que a "normalidade" entende como necessário sem, contudo, ouvir os sujeitos para as quais elas se destinam.

É importante pensar que o Movimento Social traz à esfera pública aspectos éticos fundamentais para a discussão sobre as minorias e, nesse ponto, Arroyo (1996) afirma que eles trazem a possibilidade de repor a relação entre ética e educação, na medida em que ousam questionar saberes e valores naturalizados pelas culturas, contestando práticas preconceituosas que catalogam sujeitos e silenciam as diferenças. Grande desafio está posto àqueles que adentram os espaços de educação formal e não formal, principalmente quando se trata de pensar: que contribuições o movimento organizado de pessoas com deficiência trouxe ou traz para o campo do cuidado nas diferentes 
esferas sociais: na educação, na assistência social, na saúde, na cultura e lazer, na política? Infelizmente, no Brasil as iniciativas de organização ainda são frágeis e pouco representativas, haja vista a longa história de institucionalização e tutela destes sujeitos e a fragilidade dos espaços de participação democrática de nossa jovem democracia.

Contudo há importantes contribuições dos movimentos sociais pelo mundo. A própria Convenção dos Direitos da Pessoa com Deficiência foi fruto da participação e articulação deles em diversos países, o que já produziu grandes avanços no que tange a visibilidade e o protagonismo das pessoas com deficiência. É importante salientar as contribuições do Fórum Vida Independente da Espanha, que assim como outros movimentos sociais de pessoas com deficiência, tem como lema "nada sobre mim sem mim" e já expressa a importância e a radicalidade na escuta das demandas dessa população. Numa publicação do Fórum Vida Independente, Rodrigues e Matilla (2015) salientam aspectos que consideram fundamentais para a efetiva inclusão social da pessoa com deficiência em igualdade de oportunidades, sendo eles a) o reconhecimento moral, ou seja, a suas vidas possuírem igual valor, b) o reconhecimento jurídico, ou seja, respaldo jurídico no direito de serem incluídas na sociedade e c) o reconhecimento social, ou seja, políticas sociais que fomentem a inclusão e a equidade. Tais reivindicações nos contam sobre como temos tratado as pessoas com deficiência no que tange, principalmente, o reconhecimento moral - não são raras as vezes em que se escuta de um professor "mas eu tenho outros trinta alunos que não podem se prejudicar". Outros trinta? Esse estudante, o chamado "aluno de inclusão, se percebe e é percebido como tendo uma vida e uma trajetória escolar de menor valor. Gonçalves-Filho (2013) nos conta que a igualdade política torna os encontros interculturais ou profissionais uma ocasião para a troca e colaboração - na dominação, a diversidade torna-se pretexto para desigualdade. 


\section{REFLEXÕES SOBRE PRÁTICAS PEDAGÓGICAS E EMANCIPAÇÃO}

Não podemos perder de vista o desafio que está posto: re-pensar práticas que promovam emancipação e permitam a superação das inúmeras formas de opressão às minorias que ocupam os bancos escolares. Para isso, o espaço pedagógico necessariamente precisa transformar-se em espaço de reconhecimento mútuo e de humanização, combatendo o sofrimento oriundo da humilhação por reconhecer-se diferente e sendo diferente, sentir-se inferior.

Paulo Freire foi um dos protagonistas na luta contra o sofrimento resultante da humilhação e da opressão em toda sua jornada. Segundo Barreto (1998), Freire viveu ao lado da classe média e da classe menos favorecida e quando criança passou fome e por várias vezes roubou açúcar de uma venda. Uma trajetória marcada por dificuldades que o fizeram trabalhar pela libertação dos oprimidos, entendendo que as situações de dominação não deveriam ser naturalizadas e descontextualizadas. Era, como ele mesmo se definia, um esperançoso e afirmava: "eu sonho como uma sociedade reinventando-se de baixo para cima, em que as massas populares tenham, na verdade, o direito de ter voz, e não o dever de apenas escutar" (FREIRE, 1985, p.94).

O sonho de Freire, materializado em sua obra e em toda a sua ação no mundo, concebia uma Educação Democrática e Popular enquanto prática que possibilitaria a compreensão crítica do mundo, ou seja, levaria ao desvelamento da condição de opressão com vistas a transformação das situações que a geram. Estamos pensando aqui, que a população de pessoas com deficiência é uma população oprimida e à margem da sociedade capitalista. E é exatamente nesse ponto do discurso de Freire, que a Educação Popular e a Educação Inclusiva se encontram - pensando Inclusão como um paradigma pautado em Direitos Humanos que busca avançar na ideia da equidade e da superação das diferentes formas de exclusão escolar. Nesse aspecto podemos afirmar que ambas partem dos mesmos princípios, porque se orientam na busca da libertação, ou seja, a não aceitação de uma educação que aprisiona o ser humano em nenhuma de suas dimensões (social, psicobiológica e noética). 
Como professor, Freire percebeu que a sala de aula seria um espaço propício para essa libertação e suas práticas pedagógicas as ferramentas dignas que desatariam as pessoas de um sistema capitalista e classificatório. $\mathrm{O}$ direito de ter voz, ou seja, o diálogo que se estabelece nesse espaço, é fundamental para transformação dos sujeitos e para torná-los conscientes a partir da relação entre as pessoas, principalmente no que se refere à relação entre professoraluno.

Dialogar é uma necessidade existencial que tem caráter transformador. Porém, que lugar o diálogo tem ocupado nas famílias, na escola, nas comunidades? Como estabelecer uma relação entre as pessoas para que elas sejam protagonistas na construção de seu próprio conhecimento? Que desafios nos impõe a relação com grupos que vivem à margem da sociedade, aqueles que carregam sua bagagem étnica, cultural, social, cognitiva, racial, de gênero, porém são vistas, classificadas e reduzidas apenas à condição de "deficientes"?

Entendemos que um dos passos para qualificar as relações é ter clareza da importância do diálogo na educação, é entender que as dificuldades surgem no processo de ensino-aprendizagem quando a relação entre as pessoas é atravessada por preconceitos, fantasias, prepotência. Esse seria o ponto de partida para que processos educativos mais potentes sejam estabelecidos. No processo de ensino-aprendizagem, o "ensinar certo" significa que o papel do professor é conhecer o outro e revelar aos educandos a beleza de estarmos juntos no e com o mundo, como seres históricos que podem conhecer e intervir nesse mundo em que se está inserido. Freire (2011) traduz de forma poética este estarmos juntos quando diz " acho que uma das melhores coisas que podemos experimentar na vida, homem ou mulher, é a boniteza em nossas relações, mesmo que, de vez em quando, salpicadas de descompassos que simplesmente comprovam nossa gentetude"(pag.89).

Ensinar certo para pensar certo! Na prática, pensar certo para Freire significa pensar de forma autêntica, buscar, descobrir e entender as situações vivenciadas no sentido de perceber-se criticamente e saber de que forma estamos no mundo (FREIRE,1970). Esta forma de aprender contrapõe-se à educação tradicional, a qual limita-se à transferência inquestionável dos 
conhecimentos já produzidos e, consequentemente, torna-se excludente à medida que classifica as pessoas de acordo com sua competência cognitiva ou com a quantidade de informações que o sujeito conseguiu ou não descrever em um exame. Ainda segundo o educador, em contraposição ao que ele denominou de Educação Bancária, os processos pedagógicos deveriam primar pela confiança e pelo pensar crítico e, em sala de aula, o professor deveria ser um mediador que promove um espaço de escuta, de afetividade, de planificação e de auto-avaliação.

Novamente, trazendo Paulo Freire e seus pressupostos ao campo da educação de pessoas com deficiência, ou ao campo da educação que se dedica a pensar na diversidade de sentidos, possibilidades e trajetórias escolares, não podemos perder de vista o desafio de acessibilizar a todos e todas as possibilidades de aprendizagem que favoreçam a saída da condição de "ingenuidade" ao se apropriarem de uma leitura de mundo que permita a mobilização e o engajamento na luta pela defesa de seus diretos.

Nesse sentido, apropriar-se da linguagem como instrumento social é tarefa das mais importantes, pois teríamos a linguagem como caminho para a cidadania (FREIRE, 2011). E Paulo Freire propõe muito mais do que um processo simplista de apropriação de palavras descontextualizadas dos significados que elas tomam nos discursos pelo mundo. Para ele a alfabetização consiste no produto final de um processo de libertação, de investigação sobre a riqueza da linguagem do pensamento e do povo (FREIRE 1970).

\section{AS PRÁTICAS PEDAGÓGICAS LIBERTADORAS: APROXIMAÇÕES ENTRE AS IDEIAS DE PAULO FREIRE E MIGUEL LOPEZ MELERO}

Ainda no caminho de refletir sobre os princípios ético-políticos de Freire para a Educação de todos e todas e considerando principalmente neste momento as pessoas com deficiência, devemos fazer menção a um importante pesquisador que, desde 1977, vem se dedicando a construir uma proposta educativa pautada na democracia, na construção social do conhecimento e na valorização da diversidade em sala de aula. Miguel López Melero compartilha dos mesmos princípios de Freire: é necessário libertar as pessoas oprimidas pelo 
sistema. Iniciou sua luta pela integração de pessoas com síndrome de Down em escolas regulares entendendo esta inserção como aspecto fundamental para desenvolverem-se cognitiva e culturalmente (MELERO, 1999).

Assim como Freire, Melero busca um modelo de educação com qualidade para todos e todas, no qual ninguém seja excluído por suas condições sejam elas étnicas, de religião, de gênero, cognitivas, afetivas ou físicas. O modelo educativo proposto no Projeto Roma (MELERO, 2003) busca a humanização da escola e fundamenta-se em melhorar os contextos familiares, escolares e sociais, a partir da convivência democrática e do respeito à autonomia pessoal, social e moral dos sujeitos. A proposta do Projeto Roma é trabalhar também como projeto de investigação, na medida em que pretende produzir reflexões sobre o fato de que a inteligência se constrói, segundo ele, através do desenvolvimento de processos cognitivos, linguísticos, afetivos e de autonomia no ser humano.

Os pressupostos teórico-práticos defendidos por Freire (1970) e Melero (2003) compreendem o ser humano como ser incompleto, que necessita de aprendizagem significativa para transcender sua visão acrítica e tornar-se consciente para agir no mundo e entendem que a educação e a cultura são as únicas ferramentas que podem humaniza-los e produzir desenvolvimento. Para Freire (1970), quando o ser humano adquire consciência de sua realidade, ele pode transformar tanto seu contexto quanto a si mesmo, sendo possível, assim, comprometer-se. Melero (2003) afirma que o agir autônomo no mundo depende do quanto estamos conscientes do que fazemos e do porquê fazemos, sendo que a linguagem e a afetividade seriam elementos organizadores e catalizadores do pensamento e da ação. Contudo ele avança no sentido de afirmar que todos os seres humanos, indistintamente, são capazes de desenvolver o pensamento emancipado, livre, inclusive pessoas com comprometimentos intelectuais, físicos ou sensoriais, afirmando a importância de inverter a lógica de que a inteligência é um atributo estritamente biológico e considerando-a como fruto do processo de desenvolvimento.

Outro aspecto fundamental que os aproxima e que nos conta sobre uma prática pedagógica verdadeiramente inclusiva é a educação democrática e 
compartilhada, que não se centra na figura do professor como detentor de saber e poder. Na perspectiva freireana (FREIRE, 2011) a didática deve ser centrada nas relações entre os diferentes atores do processo educativo e não no conteúdo ou no professor. No mesmo caminho, Melero (2006) aponta que o desafio da escola que valoriza a diversidade não é só dos professores, mas de toda a comunidade escolar, que ele compreende como as famílias, o entorno social próximo e até mesmo a Universidade.

Outra grande e importante marca das ideias de Paulo Freire e Melero é a ênfase dada à importância de haver coerência entre discurso e prática, sendo que esta coerência ganhamos ao assumir que não há prática pedagógica neutra ou a-política. Melero (1999) critica veementemente práticas pedagógicas classificatórias pautadas no modelo médico-biológico (a ideologia influenciando a concepção de sujeito) que determina trajetórias a partir de um substrato biológico, desconsiderando fatores ambientais e admitindo a inteligência como uma habilidade inata. Infelizmente é esta lógica classificatória e "explicativa" da diversidade que ainda estrutura as políticas públicas, a produção de conhecimento e as práticas, dedicando-se ao estudo descontextualizado e estigmatizado da deficiência intelectual, da deficiência física, da surdez, da cegueira. Qual a coerência de se falar em políticas inclusivas e em escola para a diversidade quando os discursos e as ideologias subjacentes contam de outras lógicas? Por sua vez, Freire (2011) aponta que a impossibilidade de haver prática pedagógica neutra demanda do educador postura ética que não torne assépticos os conteúdos, mas que os considerem em espaços-tempos inundados de significados.

\section{CONSIDERAÇÕES FINAIS}

Todo este ensaio teórico buscou relacionar a importância da educação nos processos de emancipação subjetiva, política e social das Pessoas com Deficiência, considerando a importância de mudarmos a lógica discursiva que define estes sujeitos como incapazes de viver de forma digna e independente. 
Refletimos à luz das ideias de Paulo Freire e por último as aproximamos das reflexões de Miguel Lopez Melero, no sentido de resgatar a importância que estes autores dão à cultura e à construção de discursos próprios como forma de libertação das situações de opressão e invisibilidade experimentadas pelas Pessoas com Deficiência. Não podemos mais admitir estes sujeitos serem discursados por quem quer que seja, ou melhor, eles mesmos devem ter autonomia para organizarem-se politicamente para pautar suas reivindicações. Podemos e devemos estar juntos, como parceiros, porém, da mesma forma como acontece no movimento feminista, no movimento negro, o protagonismo deve ser deles.

Como educadores, devemos nos reconhecer eticamente implicados no debate acerca do verdadeiro sentido de uma cultura da diversidade dentro dos espaços escolares. Não é possível aceitar discursos "bem intencionados" que apenas reformam uma escola e um sistema que precisam ser reinventados. É claro que as mudanças sociais e culturais profundas às quais devemos nos submeter não estão circunscritas apenas à Educação, mas nela podem encontrar terreno fértil para fincar suas raízes, à medida que os espaços e as experiências educativas funcionem efetivamente, como ferramentas para ampliação de consciência sobre o ser no mundo.

Finalizamos com mais uma importante reflexão de Freire, que nos chama a pensarmos para além de determinismos genéticos, culturais ou de classe e a nos responsabilizarmos todos pelas mudanças sociais para as quais somos convocados. Para Freire (2015), importa "reconhecer que somos seres condicionados mas não determinados. Reconhecer que a história é tempo de possibilidade e não determinismo, que o futuro, permita-se-me reiterar, é problemático e não inexorável" (p.20).

\section{REFERÊNCIAS BIBLIOGRÁFICAS}

ABERLEY, P. The Concept of Opression and the Development of a Social Theory of Disability. Disability, Handicap \& Society, v. 2, n. 1, 1987. 
ARROYO, M. G. Conhecimento, ética, educação, pesquisa. Revista eCurriculum, v. 2, n. 2, jun. 2007.

BARRETO V. Paulo Freire para educadores. São Paulo: Arte \& Ciência, 1998.

BRASIL. Lei de Diretrizes e Bases da Educação Nacional, MEC, 1996;

$$
\text { Para Todos - O movimento político das pessoas com deficiência }
$$

no Brasil. SDH, 2014. Disponível em: http://www.pessoacomdeficiencia.gov.br/app/sites/default/files/arquivos/\%5Bfiel d_generico_imagens-filefield-description\%5D_2.pdf.

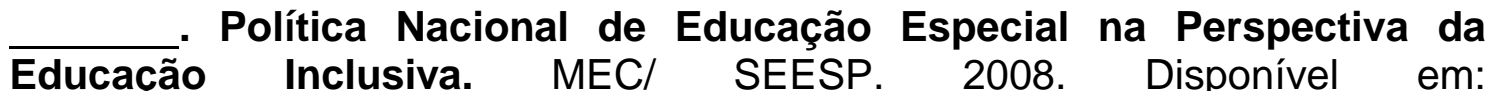
$<$ http://peei.mec.gov.br/arquivos/politica_nacional_educacao_especial.pdf >. Acesso em: 9 fev. 2016.

Decreto 6.949/2009. Promulga a Convenção Internacional dos Direitos das pessoas com Deficiência e seu Protocolo Facultativo, assinados em Nova York, em 30 de março de 2007. 2009. Disponível em: ttp://www.planalto.gov.br/ccivil_03/_ato2007-

2010/2009/decreto/d6949.htm. Acesso em: 30 jan. 2015.

Lei no 13.146 - Lei Brasileira de Inclusão da Pessoa com Deficiência, 2015. Disponível em: <http://www.planalto.gov.br/ccivil_03/_Ato20152018/2015/Lei/L13146.htm>.

FREIRE, P. Pedagogia do Oprimido. Rio de Janeiro: Paz e Terra, 1970.

FREIRE, P. O sentido da avaliação na prática de base. In: QUEIROZ, J. J. A educação popular nas comunidades eclesiais de base. São Paulo: Paulinas, 1985. p. 97-101.

FREIRE, P. Pedagogia da Esperança: o reencontro com a pedagogia do oprimido. São Paulo: Paz e Terra, 2011.

FREIRE, P. Pedagogia da Autonomia: saberes necessários à prática educativa. São Paulo: Paz e Terra, 2011.

GONÇALVES-FILHO, J. M. Humilhação social: humilhação política. In: SOUZA, B. P (Org) Orientação à queixa escolar. São Paulo: Casa do Psicólogo, 2013. p.187-221.

JANUZZI, G. M. A educação do deficiente no Brasil: dos primórdios ao início do século XXI. Campinas: Autores Associados, 2012.

MATTOS, R.A; BAPTISTA, T.W.F. Sobre Política (ou o que achamos pertinente refletir para analisar políticas). In: MATTOS, R. A.; BAPTISTA, T. W. F. (orgs.). 
Caminhos para análises de políticas de saúde. Rio de Janeiro: Instituto de Medicina Social - $\quad$ UERJ, 2011. Disponível em: <http://www.ims.uerj.br/pesquisa/ccaps/wp-content/uploads/2011/10/Caminhospara-An\%C3\%A1lises-de-Pol\%C3\%ADticas-de-Sa\%C3\%BAde.pdf>

MAZZOTA, M. J. S. Política Nacional de Educação Especial. In: Educação Especial no Brasil: história e políticas públicas. São Paulo: Cortez, 1996. p. 67-132.

MELERO, M. L. Aprendendo a conocer a las personas con síndrome de Down. Malaga: Ediciones Aljibe, 1999.

MELERO, M. L. El Proyecto Roma: una experiência de educación en valores. Málaga: Ediciones Aljibe, 2003.

MELERO, M. L. Escolas Inclusivas: o Projeto Roma. Ponto de Vista, Florianópolis, n.8, p.19-30, 2006.

RODRIGUES, A; MATILLA, P. El derecho a la inclusion de las personas discriminadas por su diversidade funcional. Foro de Vida Independiente e Diversidad.

$<\mathrm{http}: / / w w w . f o r o v i d a i n d e p e n d i e n t e . o r g / E I$ derecho_a_la_inclusion>. Acesso em: 28 fev. 2016.

SKLIAR, C. A invenção da exclusão da alteridade "deficiente" a partir dos significados da normalidade. Educação e Realidade, v. 24, n. 1, p. 15-32, jul./dez. 1999.

SKLIAR, C. A educação e a pergunta pelos Outros: diferença, alteridade, diversidade e os outros "outros". Ponto de Vista. Florianópolis, v. 5, p.37-49, 2003. 